\title{
Vital Signs: Changes in Opioid Prescribing in the United States, 2006-2015
}

\author{
Gery P. Guy Jr., $\mathrm{PhD}^{1}$; Kun Zhang, $\mathrm{PhD}^{1}$; Michele K. Bohm, $\mathrm{MPH}^{1}$; Jan Losby, $\mathrm{PhD}^{1}$; Brian Lewis ${ }^{2}$; Randall Young, $\mathrm{MA}^{2}$; \\ Louise B. Murphy, $\mathrm{PhD}^{3}$; Deborah Dowell, $\mathrm{MD}^{1}$
}

\begin{abstract}
Background: Prescription opioid-related overdose deaths increased sharply during 1999-2010 in the United States in parallel with increased opioid prescribing. CDC assessed changes in national-level and county-level opioid prescribing during 2006-2015.
\end{abstract}

Methods: CDC analyzed retail prescription data from QuintilesIMS to assess opioid prescribing in the United States from 2006 to 2015, including rates, amounts, dosages, and durations prescribed. CDC examined county-level prescribing patterns in 2010 and 2015.

Results: The amount of opioids prescribed in the United States peaked at 782 morphine milligram equivalents (MME) per capita in 2010 and then decreased to 640 MME per capita in 2015. Despite significant decreases, the amount of opioids prescribed in 2015 remained approximately three times as high as in 1999 and varied substantially across the country. County-level factors associated with higher amounts of prescribed opioids include a larger percentage of nonHispanic whites; a higher prevalence of diabetes and arthritis; micropolitan status (i.e., town/city; nonmetro); and higher unemployment and Medicaid enrollment.

Conclusions and Implications for Public Health Practice: Despite reductions in opioid prescribing in some parts of the country, the amount of opioids prescribed remains high relative to 1999 levels and varies substantially at the county-level. Given associations between opioid prescribing, opioid use disorder, and overdose rates, health care providers should carefully weigh the benefits and risks when prescribing opioids outside of end-of-life care, follow evidence-based guidelines, such as CDC's Guideline for Prescribing Opioids for Chronic Pain, and consider nonopioid therapy for chronic pain treatment. State and local jurisdictions can use these findings combined with Prescription Drug Monitoring Program data to identify areas with prescribing patterns that place patients at risk for opioid use disorder and overdose and to target interventions with prescribers based on opioid prescribing guidelines.

\section{Introduction}

In 2015, drug overdoses accounted for 52,404 deaths in the United States, $63.1 \%$ of which involved an opioid (1). Among opioid-related deaths, approximately 15,000 (approximately half) involved a prescription opioid (2). In addition, an estimated 2.0 million persons in the United States had opioid use disorder (addiction) associated with prescription opioids in 2015 (3). The economic burden of prescription opioid overdose, abuse, and dependence is estimated to be $\$ 78.5$ billion each year in the United States (4). Prescription opioid-related overdose deaths and admissions for treatment of opioid use disorder have increased in parallel with increases in opioids prescribed in the United States, which quadrupled from 1999 to 2010 (5). This increase was primarily because of an increase in the use of opioids to treat chronic noncancer pain $(6,7)$. Previously, opioids had primarily been reserved for severe acute pain, postsurgical pain, and end-of-life care. This change in prescribing practice increased the amount of opioids prescribed for three reasons. First, opioid use for chronic noncancer pain increased the number of opioid prescriptions. Second, the use of opioids to treat ongoing chronic conditions increased the average lengths of time for which opioids were prescribed $(6,7)$. Third, average dosages of opioid prescriptions tend to be higher for patients who are prescribed opioids for long periods of time, effectively increasing the average amount of opioids supplied per prescription $(6,7)$. Together, these changes placed more persons at risk for opioid use disorder and overdose (8-11).

Chronic pain is one of the most common reasons for seeking medical attention in the United States, and prescription opioids are frequently prescribed to manage pain (12). However, opioids should only be used when benefits are expected to outweigh risks. Ensuring that patients have access to safe, effective treatment is critical and involves improving the way opioids are prescribed. To improve understanding of opioid prescribing trends in the United States before the release of CDC's 2016 Guideline for Prescribing Opioids for Chronic Pain 


\section{Key Points}

- The amount of opioids prescribed in the United States peaked in 2010 and then decreased each year through 2015. Despite reductions, the amount of opioids prescribed remains approximately three times as high as in 1999.

- Opioid prescribing varied substantially across the country, with average per capita amounts prescribed in the top-prescribing counties approximately six times the amounts prescribed in the lowest prescribing counties in 2015.

- Higher amounts of opioids were prescribed in counties with a larger percentage of non-Hispanic whites; a higher prevalence of diabetes and arthritis; micropolitan counties; and counties with higher rates of unemployment and Medicaid enrollment.

- The substantial variation in opioid prescribing observed at the county-level suggests inconsistent practice patterns and a lack of consensus about appropriate opioid use and demonstrates the need for better application of guidance and standards around opioid prescribing practices.

- Health care providers can follow the CDC's Guideline for Prescribing Opioids for Chronic Pain, which provides evidence-based recommendations about opioid prescribing for primary care clinicians treating adult patients with chronic pain, outside of active cancer treatment, palliative care, and end-of-life care.

- Additional information is available at https://www.cdc. gov/vitalsigns/.

(Guideline), CDC analyzed changes in national and countylevel opioid prescribing and characteristics associated with higher prescribing rates at the county-level (13).

\section{Methods}

Data on opioid prescribing come from the QuintilesIMS Transactional Data Warehouse, which provides estimates of the number of opioid prescriptions dispensed in the United States based on a sample of approximately 59,000 pharmacies, representing $88 \%$ of prescriptions in the United States.

Changes in opioid prescribing at the national level were analyzed from 2006 to 2015 . Prescribing rates included overall opioid prescribing rates, high-dose prescribing rates, and prescribing rates by days' supply ( $\geq 30$ days and $<30$ days). Annual opioid prescribing rates were calculated by dividing the number of opioid prescriptions by the U.S. Census population estimates each year. High-dose prescribing rates include prescriptions with daily dosage $\geq 90$ morphine milligram equivalents (MME) (13). All rates are per 100 persons. Additional measures included MME per capita, average daily MME per prescription, and average days' supply per prescription. Cold and cough products containing opioids and buprenorphine products indicated for conditions other than pain were excluded.

To determine where prescribing changes occurred, opioid prescribing at the county level was examined in 2010 (when prescribing levelled off nationally) and 2015. Quartiles were created using MME per capita to characterize the distribution of opioids prescribed. The percentage of counties experiencing changes in opioid prescribing measures from 2010 to 2015 was calculated. A change of $\geq 10 \%$ was considered to be an increase or decrease, whereas changes $<10 \%$ were considered stable. County-level characteristics were examined in 2015 by MME per capita quartiles. County characteristics were obtained from the U.S. Census Bureau (age, urban/rural status); American Community Survey (race/ethnicity, percent uninsured, percent unemployed, income); U.S. Diabetes Surveillance System (diabetes prevalence); Dartmouth Atlas of Health Care (provider supply); Centers for Medicare and Medicaid Services (Medicaid and Medicare coverage); Behavioral Risk Factor Surveillance System (arthritis prevalence); and the Area Health Resource File (percent disabled, suicide rate). To identify county-level factors associated with MME per capita in 2015, a stepwise multivariable linear regression model incorporating age, race/ ethnicity, insurance status, education, unemployment rates, poverty rates, median income, urban/rural status (metropolitan, micropolitan [i.e., town/city; nonmetro], and noncore [i.e., rural; nonmetro]), suicide rates, dentist and primary care physician density, and diabetes, arthritis, and disability prevalence was estimated.

\section{Results}

In the United States, annual opioid prescribing rates increased from 72.4 to 81.2 prescriptions per 100 persons from 2006 to 2010 , were constant from 2010 to 2012 , and then decreased by $13.1 \%$ to 70.6 per 100 persons from 2012 to 2015 (Figure 1). Annual high-dose opioid prescribing rates remained stable from 2006 to 2010 and then declined by $41.4 \%$ from 11.4 per 100 persons in 2010 to 6.7 in 2015. Annual prescribing rates for prescriptions of $\geq 30$ days' supply increased $58.9 \%$ from 17.6 per 100 persons in 2006 to 28.0 per 100 persons in 2012 and leveled off from 2012 to 2015. Annual prescribing rates for prescriptions of $<30$ days' supply were stable from 2006 to 2012 and decreased $20.2 \%$ from 53.2 per 100 persons in 2012 to 42.4 in 2015. Average daily MME per prescription remained stable from 2006 to 2010 and then decreased $16.9 \%$ from 58.0 in 2010 to 
FIGURE 1. Annual opioid prescribing rates, by number of days' supply, average daily morphine milligram equivalent (MME) per prescription, and average number of days' supply per prescription — United States, 2006-2015
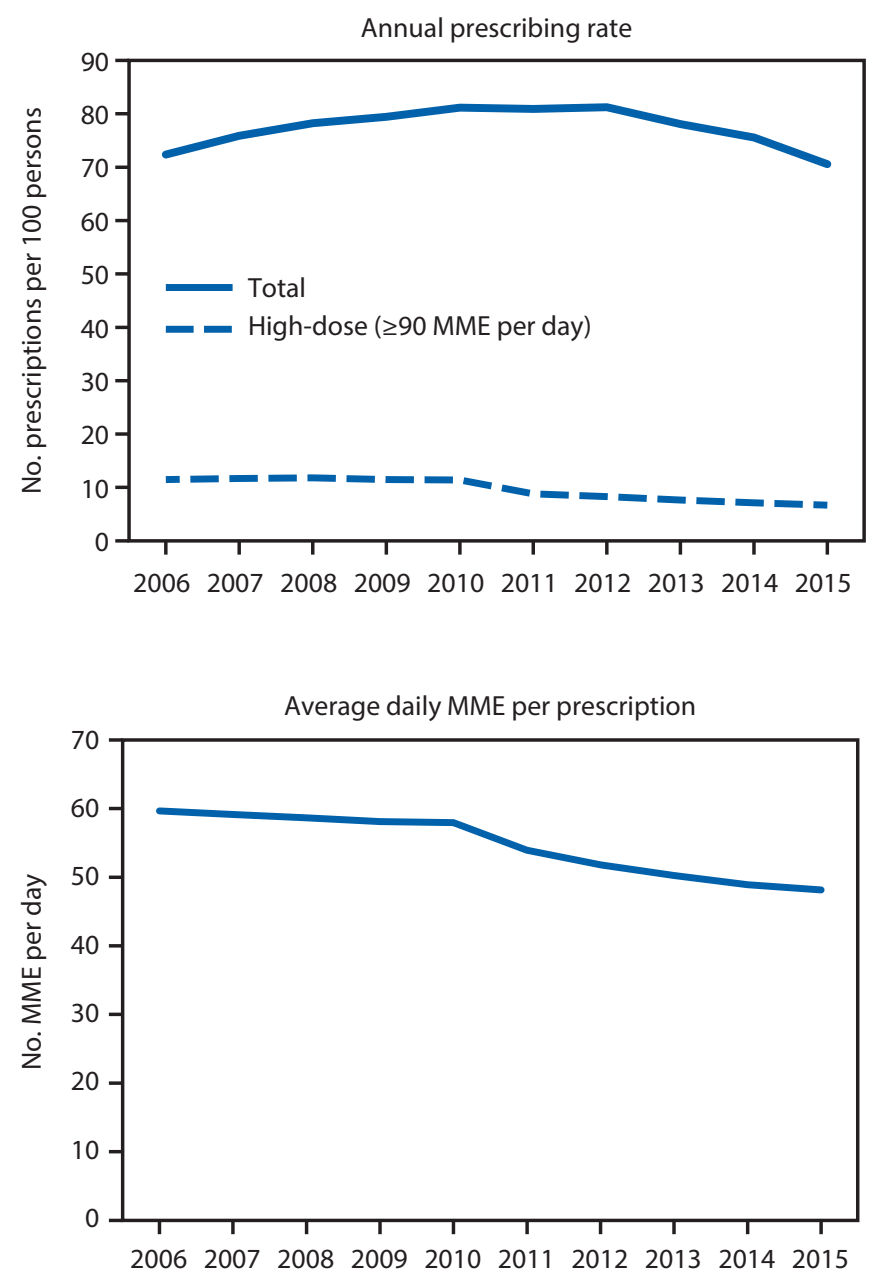

48.1 in 2015. Average days' supply prescribed increased 33.0\% from 13.3 in 2006 to 17.7 in 2015.

From 2010 to 2015, the amount of opioids prescribed in the United States decreased from 782 to 640 MME per capita (data not shown). In 2010 and 2015, the amount of opioids prescribed across counties varied substantially (Figure 2). From 2010 to 2015, among counties with sufficient data MME per capita decreased in $49.6 \%$ of counties, remained stable in $27.8 \%$ of counties, and increased in $22.6 \%$ of counties (Table 1). Overall prescribing rates decreased in nearly half $(46.5 \%)$ of counties, whereas high-dose opioid prescribing rates and average daily MME per prescription decreased in the majority of counties, with $86.5 \%$ and $72.1 \%$ of counties, respectively, experiencing decreases. From 2010 to 2015, average number of days' supply increased in $73.5 \%$ of counties.

Despite reductions in prescribing, the amount of opioids prescribed in 2015 remained high relative to 1999 levels and varied substantially across the country, from an average of
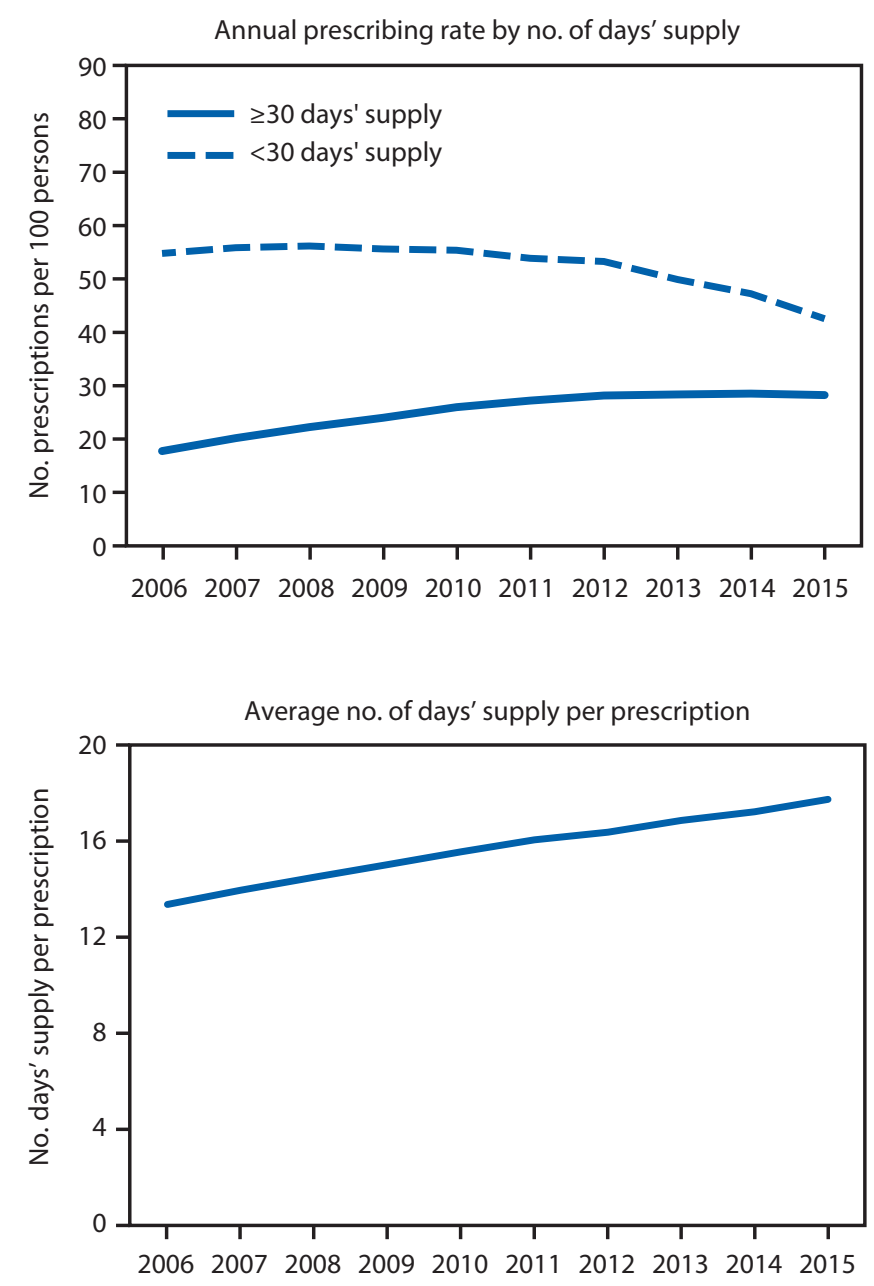

203 MME per capita in the lowest quartile to 1,319 MME per capita in the highest quartile. Opioid prescribing amounts varied across several county-level characteristics (Table 2). After adjustment in the multivariable model, the following characteristics were associated with higher amounts of opioids prescribed: a larger percentage of non-Hispanic whites; higher rates of uninsured and Medicaid enrollment, lower educational attainment; higher rates of unemployment; micropolitan status; more dentists and physicians per capita; a higher prevalence of diagnosed diabetes, arthritis, and disability; and higher suicide rates. Together, these factors explain approximately $32 \%$ of the variation in the amount of opioids prescribed at the county-level.

\section{Discussion}

The amount of opioids prescribed in the United States began to decrease in 2011. However, in 2015, at 640 MME per capita, it remains approximately three times as high as in 1999, when 
FIGURE 2. Morphine milligram equivalents (MMEs) of opioids prescribed per capita in 2015 and change in MMEs per capita during 2010-2015, by county — United States, 2010-2015

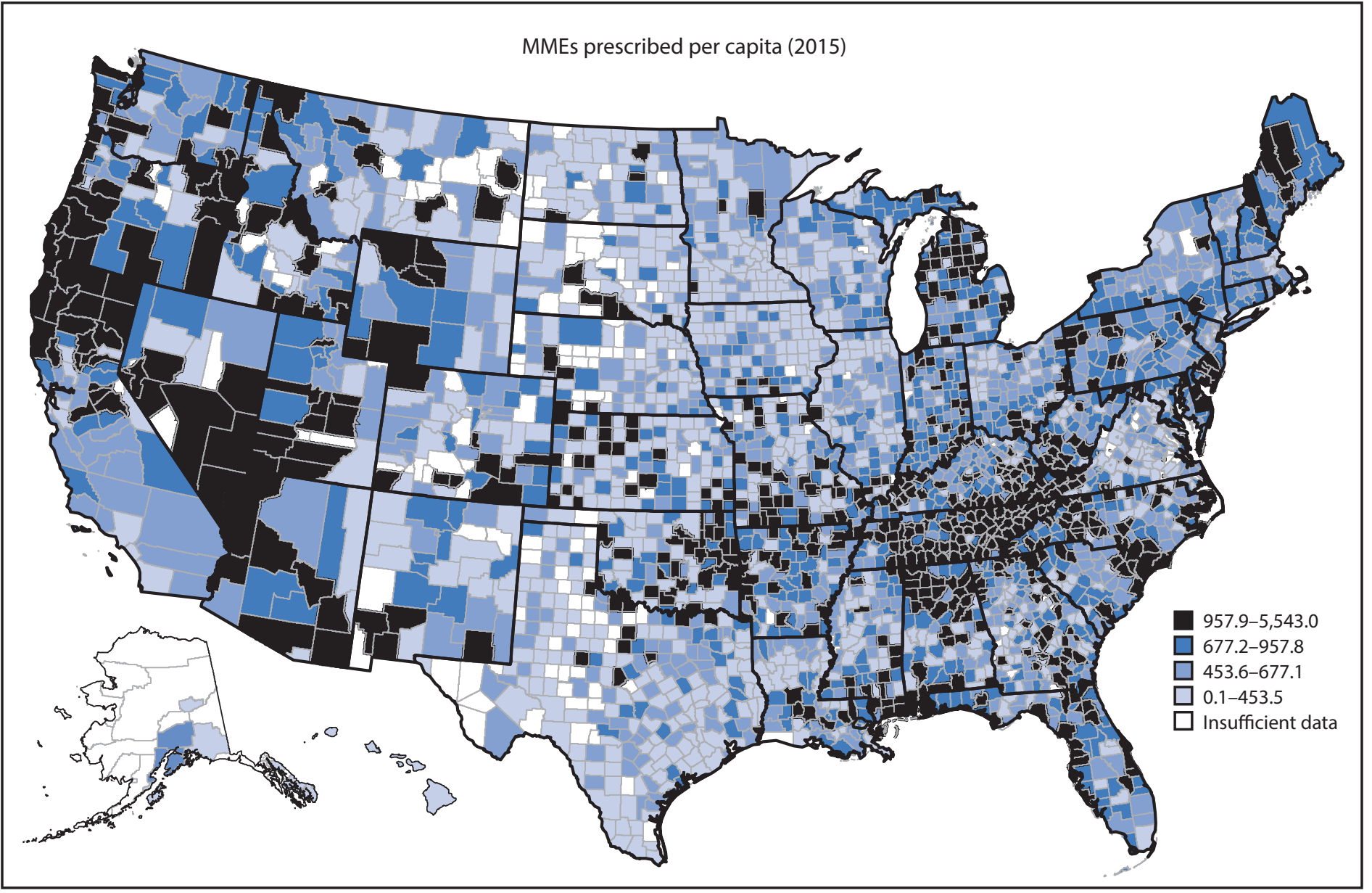

180 MME per capita were sold in the United States (5), and nearly four times as high as the amount distributed in Europe in 2015 (14).

Two prescribing changes appear to be associated with the decrease in MME prescribed per capita in the United States from 2010 to 2015. First, average daily MME per prescription decreased after 2010, both nationwide and in most counties. The largest decreases occurred from 2010 to 2012, following publication of two national guidelines defining high-dose opioid prescribing as $>200 \mathrm{MME} /$ day $(15,16)$. It also coincided with studies demonstrating progressively increasing overdose risk at prescribed opioid dosages exceeding 20, 50, and 100 MME per day (9-11) and publications highlighting associations of prescribed opioids with overdose deaths $(5,17)$. Second, the rate of opioid prescribing decreased nationwide and in many counties. Nationally, opioid prescribing rates leveled off from 2010 to 2012, and then decreased by $13.1 \%$ from 2012 to 2015 . These decreases might reflect growing awareness among clinicians and patients of the risks associated with opioids. Throughout this period, however, the average duration of opioid prescriptions increased, in part because of the continued increase in longer opioid prescriptions ( $\geq 30$ days) through 2012 , followed by a stabilization of the rate, and a substantial decrease in shorter prescriptions ( $<30$ days) after 2012. This pattern, along with the trends in overall numbers of opioid prescriptions, might reflect fewer patients initiated on opioid therapy after 2012, whereas patients already receiving opioids were more likely to continue receiving them. Patients are at risk for continuing opioids long-term once they have received them for $>5$ days (18), and are unlikely to discontinue opioids after they have received them for 90 days (19), highlighting both the importance of minimizing unnecessary initial opioid exposure and potential challenges in reducing opioid use among patients already receiving them.

From 2010 to 2015, half of counties in the United States experienced reductions in the amount of opioids prescribed, with substantial decreases in certain states. In 2011 and 2012, Ohio and Kentucky, respectively, mandated that clinicians review Prescription Drug Monitoring Program (PDMP) data and implemented pain clinic regulation (20). MME per capita 


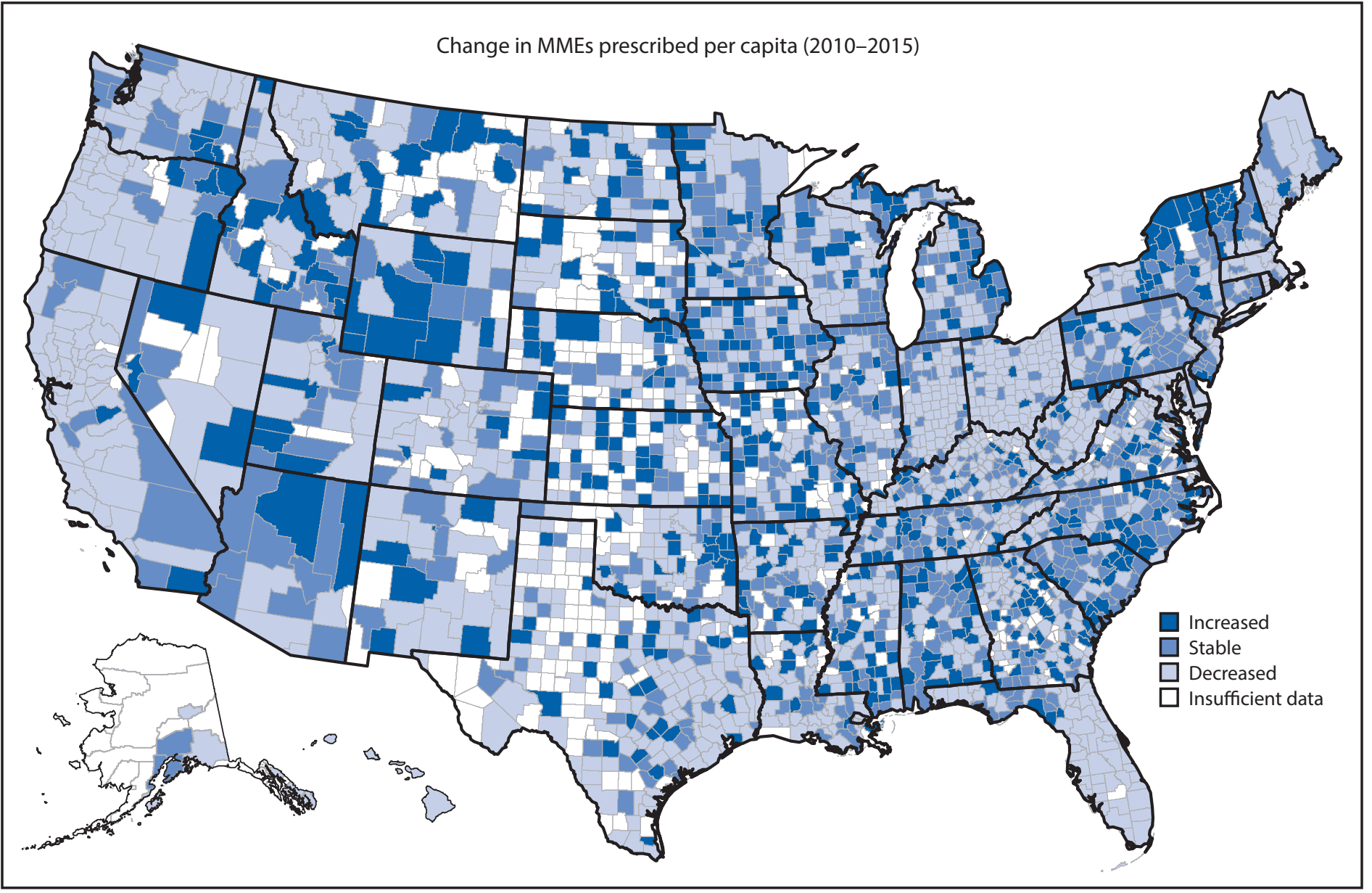

decreased in $85 \%$ of Ohio counties and $62 \%$ of Kentucky counties from 2010 to 2015. In Florida, where multiple interventions targeted excessive opioid prescribing from 2010 through 2012, (e.g., pain clinic regulation and mandated PDMP reporting of dispensed prescriptions) (21), the amount of opioids prescribed per capita decreased in $80 \%$ of counties from 2010 to 2015. During this time, Florida also experienced reductions in prescription opioid-related overdose deaths (21).

Despite reductions, the amount of opioids prescribed in 2015 remained high relative to 1999 levels and varied substantially across the country, with average per capita amounts prescribed in the top quartile of counties approximately six times the amounts prescribed in the lowest quartile. Larger amounts were prescribed in micropolitan counties and in counties with a higher prevalence of diagnosed diabetes and arthritis. The latter finding might represent treatment for pain associated with these or co-occurring painful conditions. However, there are effective nonopioid treatments for pain whose benefits outweigh the harms (13). Reasons for higher opioid use in micropolitan counties might include less access to quality health care and other treatments for pain, such as physical therapy. In addition, persons in rural areas might travel to micropolitan areas, which often serve as an anchor community for a much larger rural region, to receive medical care and pick up medications.

Despite reductions in opioid prescribing in recent years, opioid-involved overdose death rates continue to increase. However, these increases have been driven largely by use of illicit fentanyl and heroin (1). There is no evidence that policies designed to reduce inappropriate opioid prescribing are leading to these increases. Combined implementation of mandated provider review of PDMP data and pain clinic laws reduced the amount of opioids prescribed, prescription opioidinvolved overdose deaths, and all opioid-involved deaths (20). The policies were also associated with reductions in heroin overdose deaths that were not statistically significant (20). By reducing the number of persons exposed to opioids and the subsequent risk of opioid use disorder these policies might reduce the number of persons initiating illicit opioid use in the longer term (20). 
TABLE 1.Percentage of counties with changes* in opioid prescribing United States, 2010-2015

\begin{tabular}{lccc}
\hline Opioid prescribing measures & $\begin{array}{c}\text { Decrease } \\
\text { (\%) }\end{array}$ & $\begin{array}{c}\text { Stable } \\
(\%)\end{array}$ & $\begin{array}{c}\text { Increase } \\
(\%)\end{array}$ \\
\hline MME per capita & 49.6 & 27.8 & 22.6 \\
Overall prescribing rate $^{\text {I\% }}$ & 46.5 & 33.8 & 19.6 \\
High-dose $^{\dagger}$ prescribing rate & 86.5 & 6.7 & 6.9 \\
Average daily MME per prescription & 72.1 & 25.7 & 2.2 \\
Average days' supply per prescription & 1.1 & 25.4 & 73.5 \\
\hline
\end{tabular}

Abbreviation: $\mathrm{MME}=$ morphine milligram equivalent.

* Among counties with sufficient data, changes of $\geq 10 \%$ were considered to represent an increase or decrease, whereas changes of $<10 \%$ were considered stable.

† High-dose prescribing rates include prescriptions with daily dosage $\geq 90 \mathrm{MME}$.
The findings in this report are subject to at least four limitations. First, QuintilesIMS estimates of dispensed prescriptions have not been validated, and they do not include prescriptions dispensed directly by prescribers (although this likely represents a small minority of prescribed opioids), potentially biasing opioid prescribing downwards. Second, county-level analyses are aggregated by the county where an opioid is dispensed, and cannot account for prescriptions obtained by persons outside of the county. Third, the analysis does not include clinical outcomes. However, previous analyses have found associations between population-level amounts of opioids prescribed

TABLE 2. Sociodemographic characteristics of counties by MME per capita quartiles* - United States, 2015

\begin{tabular}{|c|c|c|c|c|c|c|c|}
\hline \multirow[b]{2}{*}{ Characteristics } & \multirow[b]{2}{*}{ Total } & \multirow{2}{*}{$\begin{array}{l}\text { Lowest } \\
\text { quartile }\end{array}$} & \multirow{2}{*}{$\begin{array}{l}\text { Second } \\
\text { quartile }\end{array}$} & \multirow{2}{*}{$\begin{array}{c}\text { Third } \\
\text { quartile }\end{array}$} & \multirow{2}{*}{$\begin{array}{l}\text { Highest } \\
\text { quartile }\end{array}$} & \multicolumn{2}{|c|}{ Adjusted results ${ }^{\dagger}$} \\
\hline & & & & & & Coefficient & p-value \\
\hline Population no. (\%) & - & $\begin{array}{r}76,225,923 \\
(23.8)\end{array}$ & $\begin{array}{r}108,825,101 \\
(33.9)\end{array}$ & $\begin{array}{r}83,254,830 \\
(26.0)\end{array}$ & $\begin{array}{r}52,330,662 \\
(16.3)\end{array}$ & - & - \\
\hline Average MME per capita & - & 202.9 & 528.5 & 776.9 & $1,318.7$ & - & - \\
\hline \multicolumn{8}{|l|}{ Age group, yrs (\%) } \\
\hline$<35$ & 43.3 & 43.2 & 44.6 & 43.3 & 42.1 & NA & - \\
\hline $35-64$ & 38.8 & 38.6 & 38.7 & 38.9 & 39.0 & NA & - \\
\hline$\geq 65$ & 17.9 & 18.2 & 16.7 & 17.7 & 18.9 & NA & - \\
\hline \multicolumn{8}{|l|}{ Race/Ethnicity (\%) } \\
\hline Non-Hispanic white & 80.1 & 76.9 & 78.3 & 81.8 & 83.6 & 6.9 & $<0.001$ \\
\hline Non-Hispanic black & 9.0 & 9.3 & 9.4 & 9.3 & 8.0 & NA & - \\
\hline Hispanic $\S$ & 7.0 & 9.5 & 8.3 & 5.3 & 4.8 & NA & - \\
\hline Other & 3.9 & 4.4 & 4.0 & 3.7 & 3.6 & NA & - \\
\hline \multicolumn{8}{|l|}{ Insurance status (\%) } \\
\hline Uninsured & 14.9 & 15.3 & 14.3 & 14.5 & 15.7 & 7.5 & $<0.001$ \\
\hline Medicare & 16.8 & 17.2 & 15.8 & 16.7 & 17.7 & NA & - \\
\hline Medicaid & 20.6 & 19.2 & 19.3 & 20.7 & 23.3 & 5.3 & $<0.001$ \\
\hline \multicolumn{8}{|l|}{ Education level (\%) } \\
\hline No high school diploma & 16.9 & 17.3 & 15.9 & 16.1 & 18.4 & 6.9 & $<0.001$ \\
\hline \multicolumn{8}{|l|}{ Employment level (\%) } \\
\hline Unemployed & 7.6 & 6.7 & 7.3 & 7.9 & 8.5 & 11.0 & $<0.001$ \\
\hline \multicolumn{8}{|l|}{ Income } \\
\hline Income below the Federal Poverty Level (\%) & 15.5 & 15.3 & 14.5 & 15.2 & 17.1 & -3.8 & 0.08 \\
\hline Median annual income (\$) & 22,479 & 22,339 & 23,747 & 22,612 & 21,216 & NA & - \\
\hline \multicolumn{8}{|l|}{ Urban/Rural (\%) } \\
\hline Metropolitan & 38.5 & 29.5 & 47.9 & 41.9 & 34.7 & 0.6 & 0.003 \\
\hline Micropolitan & 21.6 & 13.6 & 20.2 & 24.9 & 27.6 & 1.3 & $<0.001$ \\
\hline Noncore & 39.9 & 56.9 & 31.9 & 33.2 & 37.7 & NA & - \\
\hline \multicolumn{8}{|l|}{ Provider density per 100,000 residents } \\
\hline Primary care physicians (no.) & 55.2 & 44.1 & 57.4 & 59.5 & 60.0 & 2.1 & $<0.001$ \\
\hline Dentists (no.) & 38.2 & 30.5 & 41.5 & 41.3 & 39.5 & 4.0 & $<0.001$ \\
\hline \multicolumn{8}{|l|}{ Disease/Condition prevalence (\%) } \\
\hline Diagnosed diabetes & 11.1 & 10.2 & 10.6 & 11.4 & 12.1 & 30.5 & $<0.001$ \\
\hline Diagnosed arthritis & 24.8 & 23.7 & 23.9 & 25.4 & 26.3 & 9.6 & 0.009 \\
\hline Disabled & 15.1 & 14.4 & 13.5 & 15.3 & 17.4 & 21.9 & $<0.001$ \\
\hline \multicolumn{8}{|l|}{ Selected death rate } \\
\hline Suicides per 100,000 (no.) & 11.3 & 7.7 & 15.1 & 13.5 & 9.0 & 10.4 & $<0.001$ \\
\hline
\end{tabular}

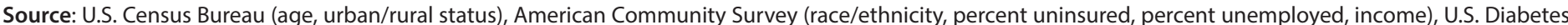

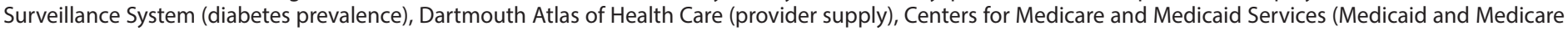
coverage), Behavioral Risk Factor Surveillance System (arthritis prevalence), and the Area Health Resource File (percent disabled, suicide rate).

Abbreviations: $\mathrm{MME}=$ morphine milligram equivalents; $\mathrm{NA}=$ not applicable (variable was not included in the final model).

* Quartiles were created using MME per capita to characterize the distribution of opioids prescribed.

† Results are from a stepwise multivariable linear regression model of the continuous variable, county-level MME per capita.

$\S$ Hispanic persons could be of any race.

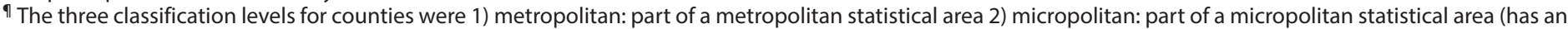
urban cluster of $\geq 10,000$ but $<50,000$ population); and 3) noncore: not part of a metropolitan or micropolitan statistical area. 
and opioid overdose death rates (5), and between prescribed dosages and individual overdose risk (9-11). Finally, because data on the indications for which opioids were prescribed were not available, the appropriateness of opioid prescriptions, or whether opioids were prescribed for acute, chronic, or end-oflife pain, could not be determined.

Although some variation in opioid prescribing is associated with characteristics such as the prevalence of possibly painful conditions (e.g., arthritis), differences in these characteristics explain only a fraction of the wide variation in opioid prescribing across the United States. This variation suggests inconsistent practice patterns and a lack of consensus about appropriate opioid use and demonstrates the need for better application of guidance and standards around opioid prescribing practices (13). CDC's Guideline provides evidence-based recommendations about opioid prescribing for primary care clinicians treating adult patients with chronic pain outside of active cancer treatment, palliative care, and end-of-life care (13). The Guideline can help providers and patients weigh the benefits and risks for opioids according to best available evidence and individual patients' needs and safely taper opioids if risks outweigh benefits. The Guideline recommends the use of nonopioid therapies, such as acetaminophen, nonsteroidal anti-inflammatory medications, exercise therapy, and cognitive behavioral therapy for chronic pain (13).

Given associations between opioid prescribing, opioid use disorder, and opioid overdose rates (5), states and local jurisdictions can use these findings to target high-prescribing areas for interventions such as academic detailing for clinicians or individual educational visits to clinicians (22), and increased access to medication-assisted treatment for patients with opioid use disorder. Innovative approaches such as virtual physical therapy sessions with pain coping skills training $(23,24)$ can be used to improve access to effective treatment for chronic pain. In addition, states can consider policies that can reduce opioid overdose, including mandated PDMP use and pain clinic laws (20). Changes in opioid prescribing can save lives. The findings of this report demonstrate that substantial changes are possible and that more are needed.

\section{Acknowledgments}

Puja Seth, PhD; Rose Rudd, MSPH; Lyna Schieber, DPhil; Felicita David, MS, National Center for Injury Prevention and Control, CDC.

\section{Conflict of Interest}

No conflicts of interest were reported.

\footnotetext{
${ }^{1}$ Division of Unintentional Injury Prevention, National Center for Injury Prevention and Control, CDC; ${ }^{2}$ Division of Toxicology and Human Health Sciences, Agency for Toxic Substances and Disease Registry, CDC; ${ }^{3}$ Division of Population Health, National Center for Chronic Disease Prevention and Health Promotion, CDC.
}

Corresponding author: Gery P. Guy Jr., GGuy@cdc.gov, 770-488-3279.

\section{References}

1. Rudd RA, Seth P, David F, Scholl L. Increases in drug and opioidinvolved overdose deaths_-United States, 2010-2015. MMWR Morb Mortal Wkly Rep 2016;65:1445-52. https://doi.org/10.15585/mmwr. mm655051e1

2. CDC. Wide-ranging online data for epidemiologic research (WONDER). Atlanta, GA: US Department of Health and Human Services, CDC, National Center for Health Statistics; 2017. https:// wonder.cdc.gov

3. Substance Abuse and Mental Health Services Administration. Prescription drug use and misuse in the United States: results from the 2015 National Survey on Drug Use and Health. Rockville, MD: Substance Abuse and Mental Health Services Administration; 2016. https://www.samhsa.gov/data/sites/default/files/NSDUH-FFR2-2015/ NSDUH-FFR2-2015.htm

4. Florence CS, Zhou C, Luo F, Xu L. The economic burden of prescription opioid overdose, abuse, and dependence in the United States, 2013. Med Care 2016;54:901-6. https://doi.org/10.1097/MLR.0000000000000625

5. Paulozzi LJ, Jones CM, Mack KA, Rudd RA. Vital signs: overdoses of prescription opioid pain relievers-United States, 1999-2008. MMWR Morb Mortal Wkly Rep 2011;60:1487-92.

6. Boudreau D, Von Korff M, Rutter CM, et al. Trends in long-term opioid therapy for chronic non-cancer pain. Pharmacoepidemiol Drug Saf 2009;18:1166-75. https://doi.org/10.1002/pds.1833

7. Von Korff M, Saunders K, Thomas Ray G, et al. De facto long-term opioid therapy for noncancer pain. Clin J Pain 2008;24:521-7. https:// doi.org/10.1097/AJP.0b013e318169d03b

8. Edlund MJ, Martin BC, Russo JE, DeVries A, Braden JB, Sullivan MD. The role of opioid prescription in incident opioid abuse and dependence among individuals with chronic noncancer pain: the role of opioid prescription. Clin J Pain 2014;30:557-64.

9. Dunn KM, Saunders KW, Rutter CM, et al. Opioid prescriptions for chronic pain and overdose: a cohort study. Ann Intern Med 2010;152:85-92. https://doi.org/10.7326/0003-4819-152-2-201001190-00006

10. Bohnert AS, Valenstein M, Bair MJ, et al. Association between opioid prescribing patterns and opioid overdose-related deaths. JAMA 2011;305:1315-21. https://doi.org/10.1001/jama.2011.370

11. Gomes T, Mamdani MM, Dhalla IA, Paterson JM, Juurlink DN. Opioid dose and drug-related mortality in patients with nonmalignant pain. Arch Intern Med 2011;171:686-91. https://doi.org/10.1001/ archinternmed.2011.117

12. Daubresse M, Chang HY, Yu Y, et al. Ambulatory diagnosis and treatment of nonmalignant pain in the United States, 2000-2010. Med Care 2013;51:870-8. https://doi.org/10.1097/MLR.0b013e3182a95d86

13. Dowell D, Haegerich TM, Chou R. CDC guideline for prescribing opioids for chronic pain-United States. MMWR Recomm Rep 2016;65(No. RR-1). https://doi.org/10.15585/mmwr.rr6501e1

14. University of Wisconsin Pain \& Policy Studies Group. Global Opioid Consumption, 2015. Madison, WI: University of Wisconsin Pain \& Policy Studies Group; 2015. http://www.painpolicy.wisc.edu/global

15. Chou R, Fanciullo GJ, Fine PG, et al.; American Pain Society-American Academy of Pain Medicine Opioids Guidelines Panel. Clinical guidelines for the use of chronic opioid therapy in chronic noncancer pain. J Pain 2009;10:113-30. https://doi.org/10.1016/j.jpain.2008.10.008

16. The Management of Opioid Therapy for Chronic Pain Working Group. VA/DoD clinical practice guideline for management of opioid therapy for chronic pain. Washington, DC: US Department of Veterans Affairs, US Department of Defense, The Management of Opioid Therapy for Chronic Pain Working Group; 2010. https://www.va.gov/ painmanagement/docs/cpg_opioidtherapy_fulltext.pdf

17. Okie S. A flood of opioids, a rising tide of deaths. N Engl J Med 2010;363:1981-5. https://doi.org/10.1056/NEJMp1011512 
18. Shah A, Hayes CJ, Martin BC. Characteristics of initial prescription episodes and likelihood of long-term opioid use-United States, 2006-2015. MMWR Morb Mortal Wkly Rep 2017;66:265-9. https:// doi.org/10.15585/mmwr.mm6610a1

19. Martin BC, Fan MY, Edlund MJ, Devries A, Braden JB, Sullivan MD. Long-term chronic opioid therapy discontinuation rates from the TROUP study. J Gen Intern Med 2011;26:1450-7. https://doi. org/10.1007/s11606-011-1771-0

20. Dowell D, Zhang K, Noonan RK, Hockenberry JM. Mandatory provider review and pain clinic laws reduce the amounts of opioids prescribed and overdose death rates. Health Aff (Millwood) 2016;35:1876-83. https://doi.org/10.1377/hlthaff.2016.0448

21. Johnson H, Paulozzi L, Porucznik C, Mack K, Herter B; Hal Johnson Consulting and Division of Disease Control and Health Promotion, Florida Department of Health. Decline in drug overdose deaths after state policy changes -Florida, 2010-2012. MMWR Morb Mortal Wkly Rep 2014;63:569-74.
22. Kattan JA, Tuazon E, Paone D, et al. Public health detailing — a successful strategy to promote judicious opioid analgesic prescribing. Am J Public Health 2016;106:1430-8. https://doi.org/10.2105/AJPH.2016.303274

23. Bennell KL, Nelligan R, Dobson F, et al. Effectiveness of an internetdelivered exercise and pain-coping skills training intervention for persons with chronic knee pain: a randomized trial. Ann Intern Med 2017;166:453-62. https://doi.org/10.7326/M16-1714

24. Heapy AA, Higgins DM, Goulet JL, et al. Interactive voice responsebased self-management for chronic back pain: the COPES Noninferiority Randomized Trial. JAMA Intern Med 2017;177:765-73. https://doi. org/10.1001/jamainternmed.2017.0223 